\title{
The Effect of Gate Existence at L Island on The Seabed Profile Due to Reclamation of Jakarta Bay
}

\author{
Harman Ajiwibowo"1 ${ }^{\# 1}$ Munawir B. Pratama ${ }^{\# 2}$ \\ \#Faculty of Civil and Environmental Engineering, Bandung Institute of Technology \\ Jalan Ganesha 10, Bandung 40132, Indonesia \\ ${ }^{1}$ harman.ajiwibowo17@gmail.com \\ ${ }^{2}$ munawirbintang@gmail.com
}

\begin{abstract}
The effect of the construction of an artificial island on the surrounding bed profile change requires evaluation, in order to mitigate any negative impact on the environment. The case of prospective $L$ Island reclamation in Jakarta Bay, Indonesia is examined. The existence of a gate at the south side of $L$ Island (south canal) is investigated to determine its impact on surrounding sea water surface elevation, tidal current, and seabed changes using hydrodynamic modeling. A field measurement is carried out and numerical modeling using Surface-water Modelling System V.8.1 (licensed) is performed. The numerical model includes inputs of normal and flood river discharges. The sea water surface elevation is found to be changing. The existence of the gate causes a $1 \mathrm{~cm}$ sea water surface elevation reduction in the south canal during flood season. The magnitude and phase of tidal current velocity also changes after the construction of the gate. The gate magnifies the current velocity peak value at the tributary near the south canal, it is almost $7.5 \mathrm{~cm} / \mathrm{sec}$ higher. The seabed profile changes a few centimeters after reclamation. The biggest seabed change is only $2.5 \mathrm{~cm}$ in one year in the west canal. Overall, the existence of the gate increases the seabed elevation in most areas, thus routine dredging maintenance will be needed in the future.
\end{abstract}

Keyword - Numerical modeling, Coastal environment, Sea water surface elevation, Tidal current, Sedimentation, L Island, Jakarta Bay Reclamation

\section{INTRODUCTION}

The development of various infrastructures in Jakarta has caused significant economic growth. Demographic growth is also significant, so more residential land is needed. The Indonesian government has approved the reclamation of new artificial islands such as the I, J, K, L, and M Islands. This development needs to be evaluated to mitigate any future negative impact. Similar studies have been carried out around the world.

The People's Republic of China (PRC) is one of the nations executing the most intensive research in coastal areas. Examples include the investigation and evaluation of the effects of land reclamation in the Yellow River Estuary, Xiamen, Jiaozhou Bay, and Haizhou Bay [1-5]. In Haizhou Bay, the impact is not only assessed for the tidal parameters but also for sedimentation processes as carried out by Gao [5]. In Yangshan Harbor, the impact of port infrastructure (forming a tidal choking) on tidal parameters is investigated [6]. The research shows that stronger tidal choking results in a faster flow and larger tidal energy flux at the choked channel, although the tidal amplitude in the inner harbor area is reduced.

Chua has also conducted similar research in Singapore Coastal Waters to determine the circulation and volume transport [7]. The research includes tidal and wind coupling, which show a correlation with tidal-induced volume flux. The research also showed that the residual effect tends to reduce the transport volume. The research then developed into a tracer and land-based pollutant study [8,9]. Studies on land reclamation have also been carried out in several other nations, such as in the Delaware Estuary, United States [10].

Examples of studies in coastal environments from other points of view are presented by Simmons[11], Zhu [13], Aragones[12], and Tang[14]. Simmons used XBeach and also employed Generalized Likelihood Uncertainty Estimation to predict coastal changes more accurately [11]. Aragones studied the impact of riverbed construction, which affected sediment grain size to the extent that the clay nearly disappeared [12]. A descent of seabed level also observed. While Zhu specifically investigated the flow movement above and below the sediment-water interface in a tidal coastal area [13].

This study is developed to investigate the effect of a smaller feature of a land reclamation, not general impact of reclamation. The gate at the south side of L Island at Jakarta Bay Indonesia becomes the topic. The targeted parameters to be investigated are the changes of sea water surface elevation, tidal current, and seabed elevation. The purpose of this study is similar to the study carried out by Tang, but focuses on a different object [14]. Related studies in the area have been conducted by Azwar, but these focus on the social and urban aspect [15]. 


\section{STUDY LOCATION AND SCENARIOS}

Jakarta is the capital city of Indonesia, the location is shown in Fig. 1a. The red box in Fig. 1a shows the coastal area of North Jakarta. While the domain of study is shown in Fig. 1b and 1c outlined by a black box. The coastal area of North Jakarta is very important for growth of Jakarta's economy. The investigated spot is owned by Taman Impian Jaya Ancol (TIJA), which is one of the leading local government-owned companies in the tourism industry. TIJA (shown as a green box in Fig. 1c) plans to develop new reclaimed area to the north.

There are two scenarios which are investigated in this study. They are the existing condition, and the reclamation plan scenario. The study domain is given in Fig. 2a and 2b. The L Island, which is owned by TIJA, is included in two scenarios, as given in Fig. 2c and 2d. Scenario A, as seen in Fig. 2c, does not include a gate at the south side of L Island (south canal). Scenario B includes a gate in the south canal (see Fig. 2d) which may affect the flow and sediment transport along the canal.

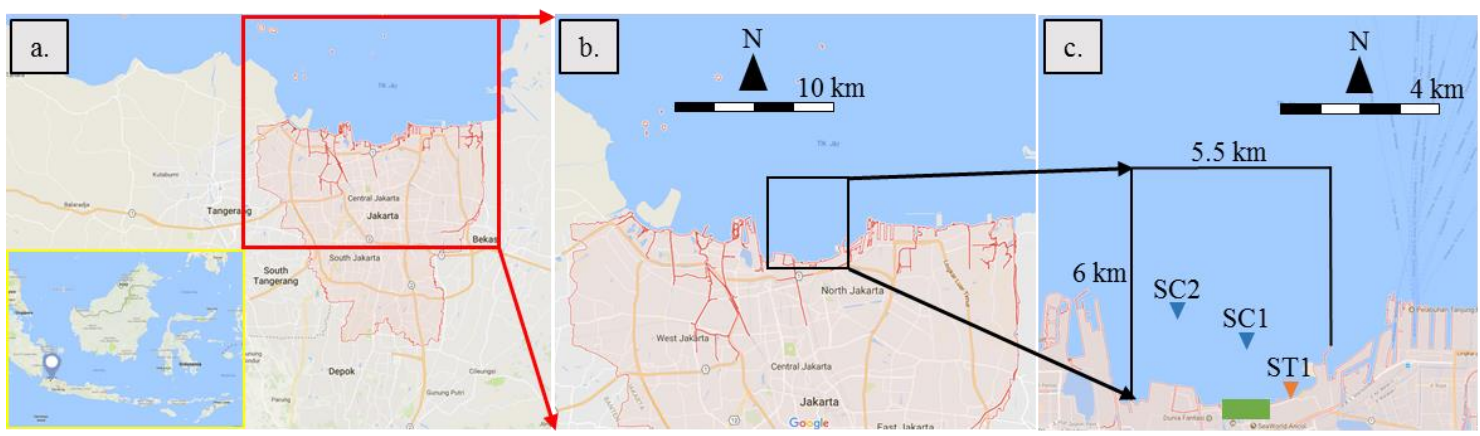

Fig. 1. Locations of (a) City of Jakarta, (b) North Jakarta Coastal Area, and (c) domain of study.
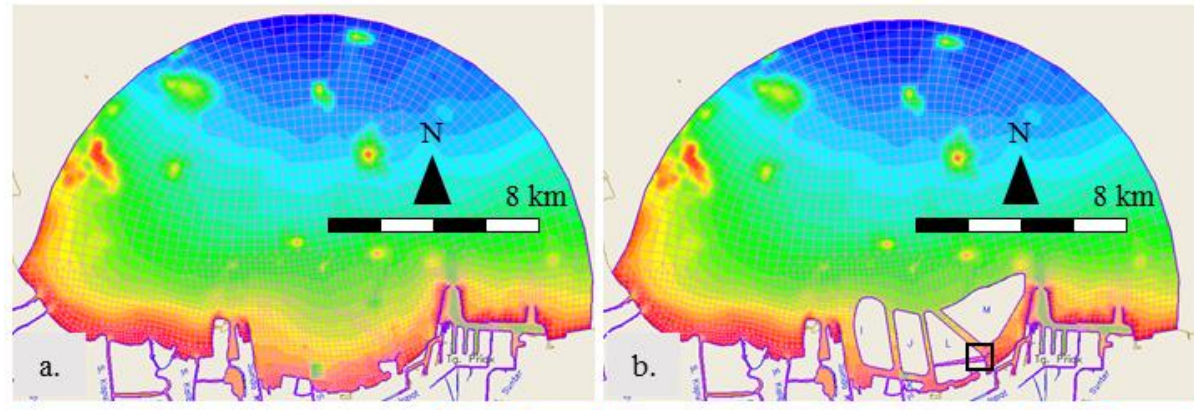

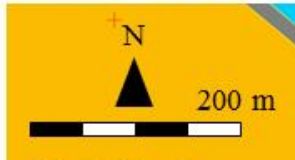

The L Island

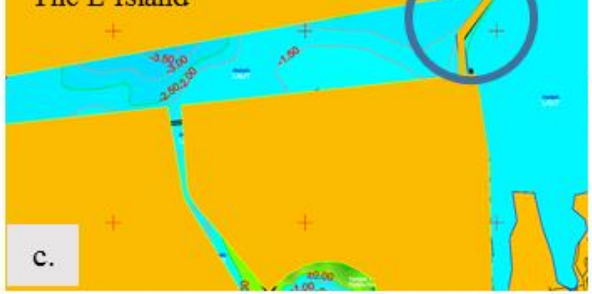

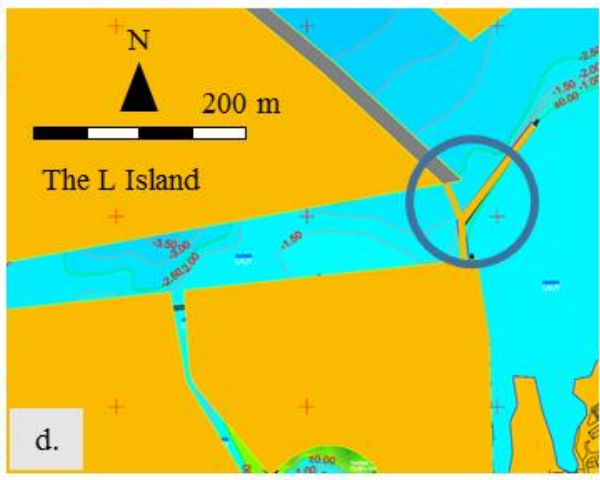

Fig. 2. The domain of (a) the existing scenario and (b) scenarios A and B, (c) scenario (model without gate) and, (d) scenario B (model with a gate at the south side of L Island).

\section{FIELd MEASUREMENT}

To provide accurate physical conditions at the study location, bathymetric, sea water surface elevation, and tidal current surveys were carried out. These similar surveys were also conducted in several previous studies [16$18]$. 


\section{A. Bathymetry}

The bathymetric survey was carried out in a $6 \times 5.5 \mathrm{~km}$ area in the North Jakarta Coastal Area (Fig. 1b). The bathymetric survey was conducted using Single Beam Echosounder (Odom Hydrotrack II). Figure 3a shows the survey equipment.
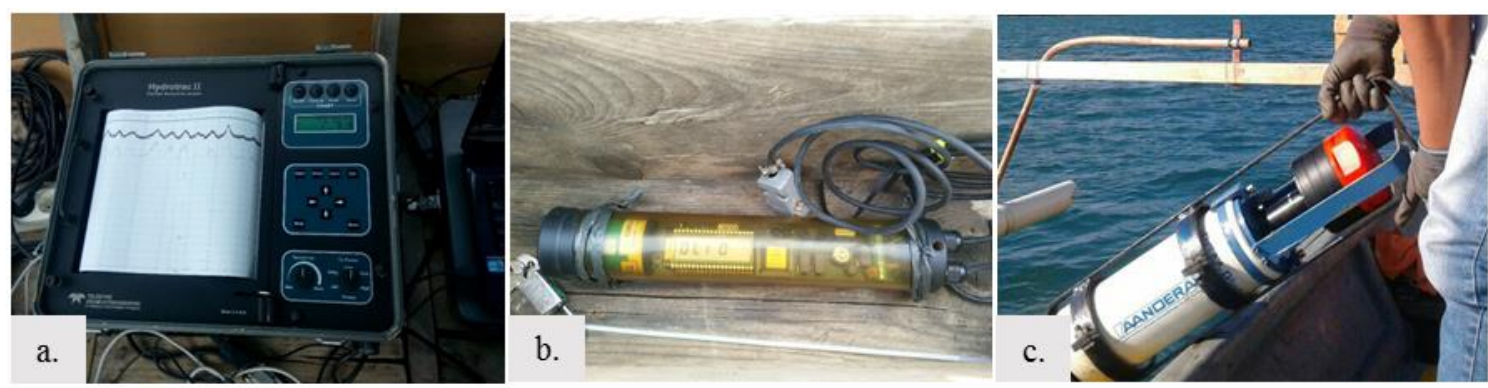

Fig. 3. (a) Echosounder, (b) AWLR, and (c) Aanderaa RCM Blue tidal current survey instruments.

\section{B. Sea water surface elevation}

Fig. 1c shows the location of the sea water surface elevation field measurement (as ST1, orange pin), and Fig.3b shows the Automatic Water Level Recorder (AWLR). The AWLR was attached to the fixed wharf. The measurement was conducted from February 19 to March 6, 2017. The measured tidal range and formzhal number are $104.52 \mathrm{~cm}$ and 4.75 , respectively. The formzhal number shows that the tidal characteristic is diurnal. The field data shows good agreement with Indonesian Navy Tide Table data, as shown in Fig.4.

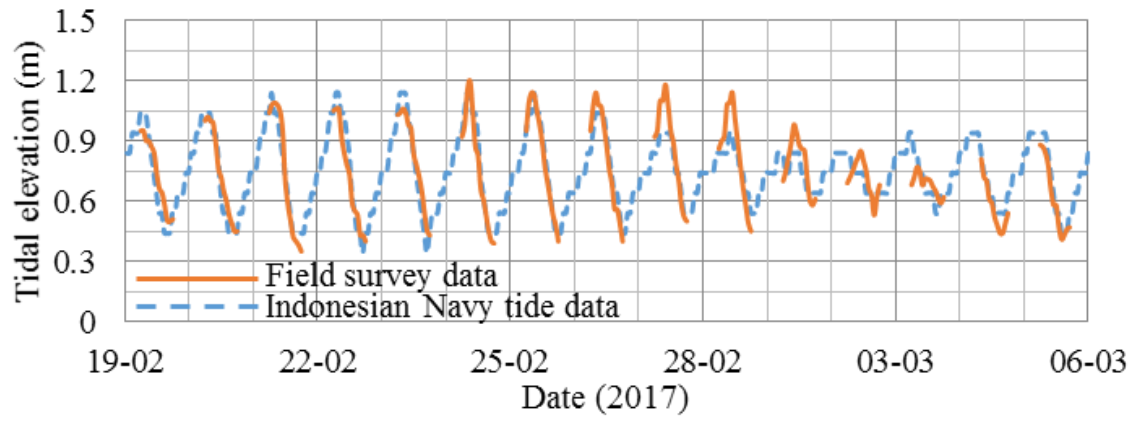

Fig. 4. The result of the sea water surface elevation field measurement at $\mathrm{T} 1$.

\section{Tidal Current Measurement}

The tidal current field measurement was carried out using Aanderaa RCM Blue (see Fig. 3c) at two locations, as given in Fig. 1c (marked as blue-pinned SC1 and SC2). The measurement was conducted at three water depths (denoted as $\mathrm{d}$ ), they are $0.2 \mathrm{~d}, 0.6 \mathrm{~d}$, and $0.8 \mathrm{~d}$. The survey was carried out for 24 hours in each location. The current at Location 1 is mainly directed to the south, as shown in Fig.5a. The current at Location 2 is mainly directed to the south or northwest, as shown in Fig.5b. Both data show that the tidal current velocity range is mostly within $0-0.1 \mathrm{~m} / \mathrm{s}$.
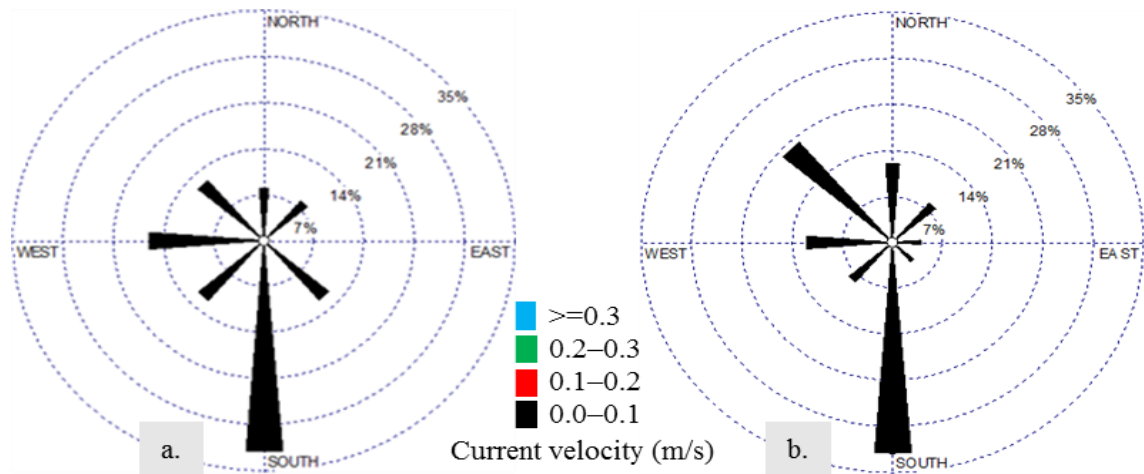

Fig. 5.The result of the tidal current survey at (a) $\mathrm{C} 1$ and (b) $\mathrm{C} 2$. 


\section{IV.NUMERICAL MODEL}

There are several modeling tools that are commonly used to model sediment transport, such as Delft3D or even primitive modeling tools $[19,20]$. However, this research uses RMA2 from Surface-water Modeling System (SMS) to model the tidal-induced current distribution in the bay, which moves the sediment across the bay. The validity level $\delta$ of the model is calculated using Eq. 1, where $\lambda_{m}$ is the value resulted from numerical model, $\lambda_{\text {field }}$ is the value obtained from field measurement [16-18], and $\sigma$ is the tidal range.

$\delta=\frac{\left|\lambda_{m}-\lambda_{\text {field }}\right|}{\sigma}$

\section{A. Governing Equations}

RMA2 V. 8.1, from Surface-water modeling system (SMS), is a 1D/2D hydrodynamic model using the finite element method. RMA2 is maintained by the Army Corps of Engineers, Engineering Resource Development Center (ERDC). RMA2 has been utilized to solve many problems over the last 40 years. Until now, it has been one of the most familiar tools.

RMA2 solves the depth-integrated equations of fluid mass (see Eq. 2) and momentum conservation in two horizontal directions (see Eq. 3 and 4 for $\mathrm{x}$ and y axis, respectively) [21].

$$
\begin{aligned}
& \frac{\partial h}{\partial t}+h\left(\frac{\partial u}{\partial x}+\frac{\partial v}{\partial y}\right)+u \frac{\partial h}{\partial x}+v \frac{\partial h}{\partial y}=0 \\
& h \frac{\partial u}{\partial t}+h u \frac{\partial u}{\partial x}+h v \frac{\partial u}{\partial y}-\frac{h}{\rho}\left[E_{x x} \frac{\partial^{2} u}{\partial x^{2}}+E_{x y} \frac{\partial^{2} u}{\partial y^{2}}\right]+g h\left[\frac{\partial a}{\partial x}+\frac{\partial h}{\partial x}\right] \\
& +\frac{g u n^{2}}{\left(1.486 h^{1 / 6}\right)^{2}}\left(u^{2}+v^{2}\right)^{1 / 2}-\zeta V_{a}^{2} \cos \psi-2 h v \omega \sin \Phi=0 \\
& h \frac{\partial v}{\partial t}+h u \frac{\partial v}{\partial x}+h v \frac{\partial v}{\partial y}-\frac{h}{\rho}\left\lfloor E_{y x} \frac{\partial^{2} v}{\partial x^{2}}+E_{y y} \frac{\partial^{2} v}{\partial y^{2}}\right]+g h\left[\frac{\partial a}{\partial y}+\frac{\partial h}{\partial y}\right] \\
& +\frac{g v n^{2}}{\left(1.486 h^{1 / 6}\right)^{2}}\left(u^{2}+v^{2}\right)^{1 / 2}-\zeta V_{a}^{2} \sin \psi+2 h u \omega \sin \Phi=0
\end{aligned}
$$

where $h$ is the water depth, $x$ and $y$ are the Cartesian coordinates, $t$ is the time, $u$ and $v$ are the velocities in Cartesian coordinates, $\rho$ is the fluid density, $E$ is the eddy viscosity coefficient, $g$ is the acceleration due to gravity, $a$ is the elevation of the bottom, $n$ is the Manning's roughness n-value, 1.486 for conversion from SI to non-SI units, $\zeta$ is the empirical wind shear coefficient, $V_{a}$ is the wind speed, $\psi$ is the wind direction, $\omega$ is the rate of Earth's angular rotation, and $\Phi$ is the local latitude.

\section{B. Model Setup}

The existing conditions at the location of interest in Jakarta Bay are presented in Fig.2a, which does not show any artificial island; In particular, there is no offshore reclamation. The scenarios, called scenarios A and B, which are based on the Government Master Plan year 2017 are shown in Figs. 2c and 2d. Both scenarios include I, J, K, $\mathrm{L}$, and $\mathrm{M}$ islands (offshore reclamation or separated from the main land) off Jakarta Coast. The domain is given in Fig. 2b. Scenario B includes a gate at the south side of the L Island or south canal (see black box in Fig.2b), which makes a closed canal at the south side as seen in Fig.2d. Scenario A does not include this, as seen in Fig.2c. The impact of the artificial islands and the gate are assessed.

The numerical modeling was performed in two dimensions (depth averaged model) with astronomical forcing as main generator for water body mass movement inside the domain. The numerical modeling consists of three stages, they are global model, local model, and scenarios model. The global model covers the Java Sea, and is validated using several sea water surface elevation and tidal current databases from the Indonesian Navy [22,23]. The boundary conditions of the global model are obtained using NaoTide [24]. 
Later, the global model surface elevation results were used to construct the local model boundary conditions. The local model was used to provide a detailed model of Jakarta Bay using bathymetric field measurement data. The domains of the global and local model are given in Fig. 6 and Fig. 7, respectively. The scenarios models are local model with modified bathymetrical chart describing artificial islands and gate. The domain of scenarios $\mathrm{A}$ and $\mathrm{B}$ are presented in Fig. 8.

The local model includes normal and flood river discharge, since Jakarta Bay is downstream of several rivers from Jakarta and the surrounding area. The included rivers are the Grogol, Ciliwung, and Sunter Rivers, denoted as D01, D02, and D03, respectively. The rivers' locations are given in Fig. 9. The normal and flood river discharge with a return period of 25 years are given in Tables I and II, respectively. All river discharges in the local model (see Figs. 7 and 8) are expressed as Q1 to Q4. The comparisons between model results using normal river discharge and flood river discharge are provided in the results and analysis chapter below.

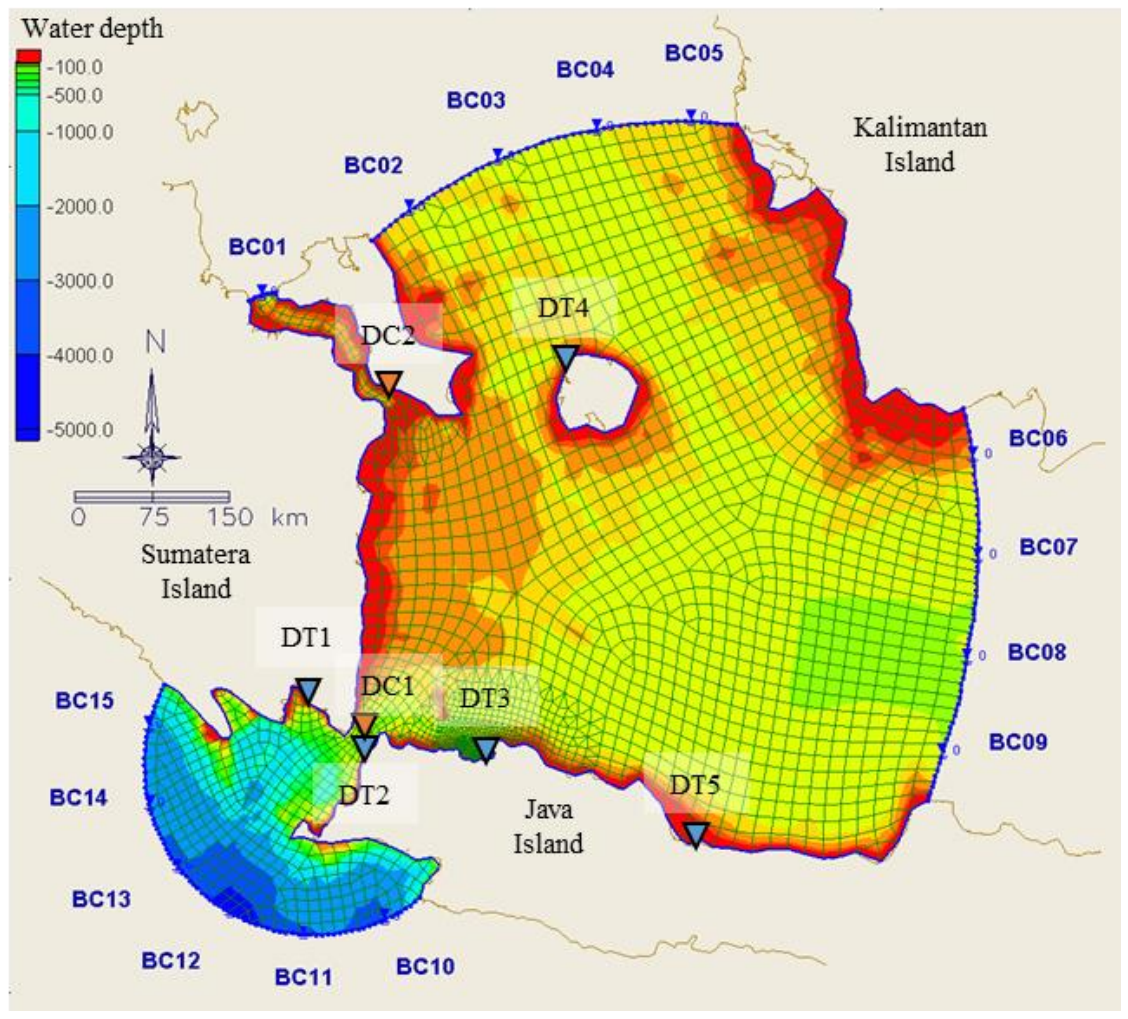

Fig. 6. Domain of global model.

TABLE I. Normal and flood discharge input.

\begin{tabular}{ccccc}
\cline { 3 - 5 } & & \multicolumn{3}{c}{ Discharge $\left(\mathrm{m}^{3} / \mathrm{s}\right)$} \\
\cline { 3 - 5 } & January & 1.18 & 48.41 & 10.08 \\
& February & 1.46 & 51.49 & 12.39 \\
& March & 1.2 & 38.59 & 11.89 \\
& April & 1.08 & 33.69 & 11.25 \\
& May & 1.01 & 32.88 & 10.4 \\
& June & 0.82 & 25.89 & 8.51 \\
& July & 0.78 & 22.52 & 7.36 \\
& August & 0.84 & 19.31 & 6.5 \\
& September & 0.88 & 24.72 & 6.41 \\
& October & 0.96 & 27.26 & 7.24 \\
& November & 1.54 & 35.05 & 8.73 \\
& December & 0.9 & 32.71 & 9.1 \\
\hline Return period & 25 years & 411.25 & 886.40 & 420.83 \\
\hline
\end{tabular}




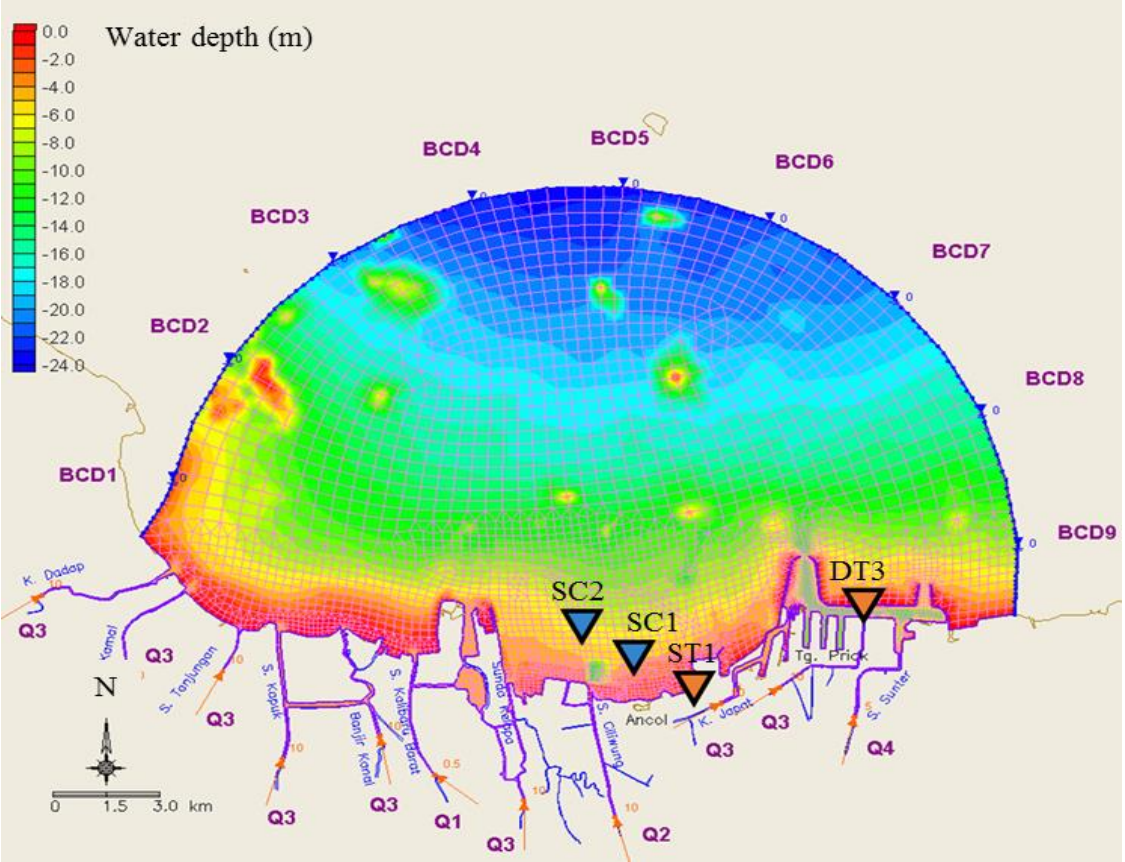

Fig. 7. Domain of local model (existing model).

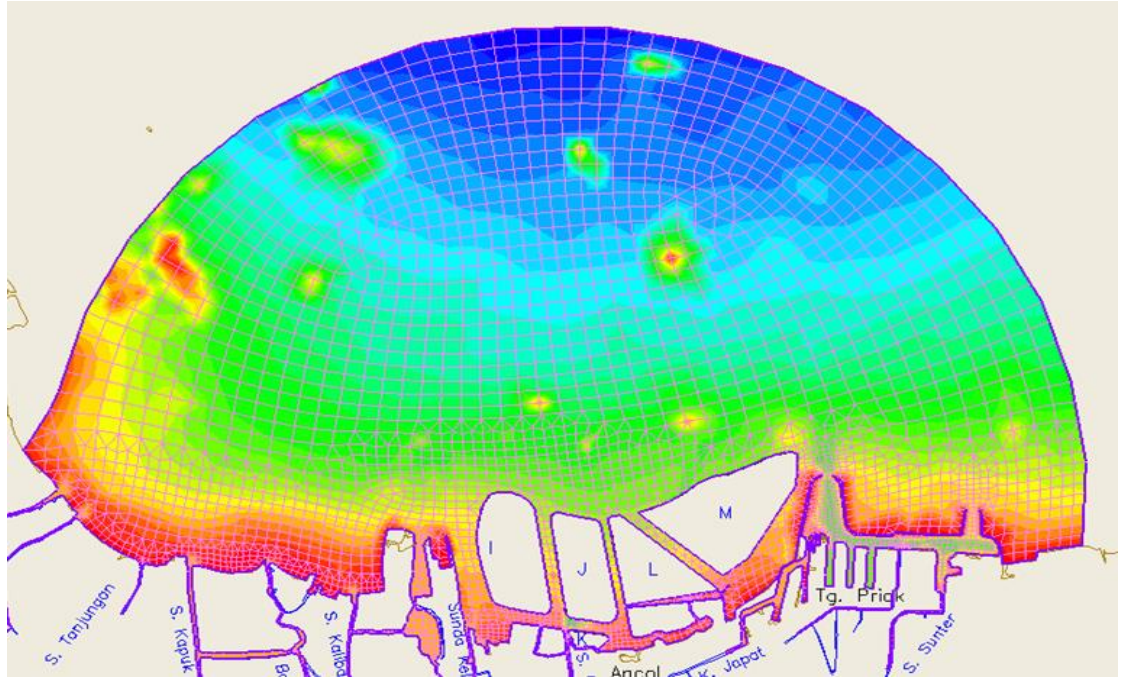

Fig. 8. Domain of scenarios model.

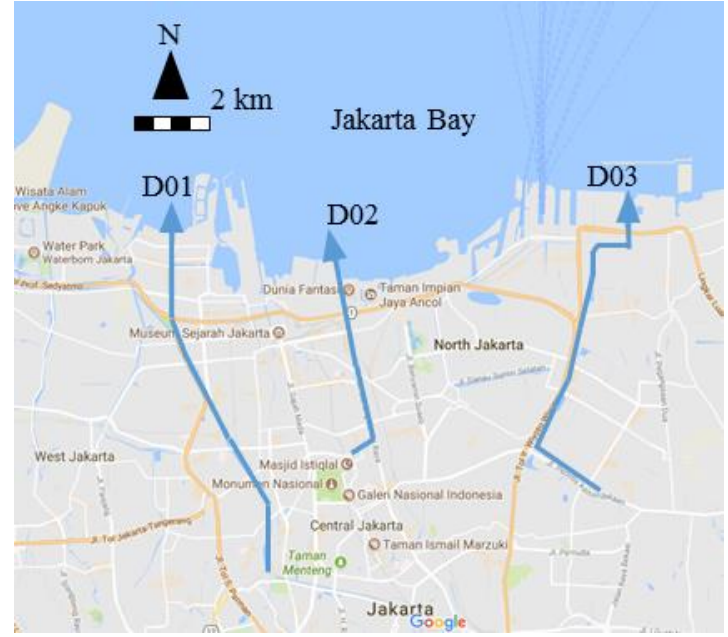

Fig. 9. Location of main rivers. 
TABLE II. River discharge equivalency to discharge input.

\begin{tabular}{cc}
\hline Unit discharge & Equivalent discharge \\
\hline Q1 & D01 \\
Q2 & D02 \\
Q3 & $1 / 3$ D02 \\
Q4 & D03 \\
\hline
\end{tabular}

\section{Model Validation}

1) Global Model Validation: The global model covers the Karimata Strait, Sunda Strait, and Java Sea. The global model tidal validations were carried out at five stations. They are Panjang, Ciwandan, Tanjung Priok, Tanjung Pandan, and Cirebon Stations (see DT1 to DT5 in Fig. 6), taken from the Indonesian Navy Tide Database [22]. The validity level results are given in Table III.

The tidal current validations were carried out at two stations, Sunda Strait and Nemesis Shoal, as shown in Fig. 6 as DC1 and DC2. Validation data were taken from the Indonesian Navy Tidal Current Database [23]. The validation results are presented in Table III, which shows an acceptable level of validity.

TABLE III. Validity level in global model validation.

\begin{tabular}{ccc}
\hline Sites & Stations & $\begin{array}{c}\text { Validity } \\
\text { Level }(\%)\end{array}$ \\
\hline DT1 & Panjang & 3.7 \\
DT2 & Ciwandan & 9.8 \\
DT3 & Tanjung Priok & 6.5 \\
DT4 & Tanjung Pandan & 5.0 \\
DT5 & Cirebon & 9.1 \\
DC1 & Sunda Strait & 7.9 \\
DC2 & Nemesis Shoal & 5.8 \\
\hline
\end{tabular}

2) Local Model Validation: The local model only covers part of Jakarta Bay. The local model tidal validations were carried out at two locations, Tanjung Priok and Ancol, denoted as DT3 and ST1 in Fig. 7. The sea water surface elevation in Tanjung Priok data (DT3) were obtained from the Indonesian Navy Tide Database [22]. Ancol sea water surface elevation data ST1 are obtained from field measurement data. The validation results are given in Fig. 10. Both validity level are $6.5 \%$.

The tidal current validations were carried out at two locations, SC1 and SC2, as shown in Fig. 7. Field measurement data were used for the validation. The validation results are presented in Fig. 11, which shows good agreement.

Since the local model has shown a good and detailed results, it was taken as the existing model. Later, the local model domain was modified to become scenarios model domain to simulate scenarios A and B with the same settings.
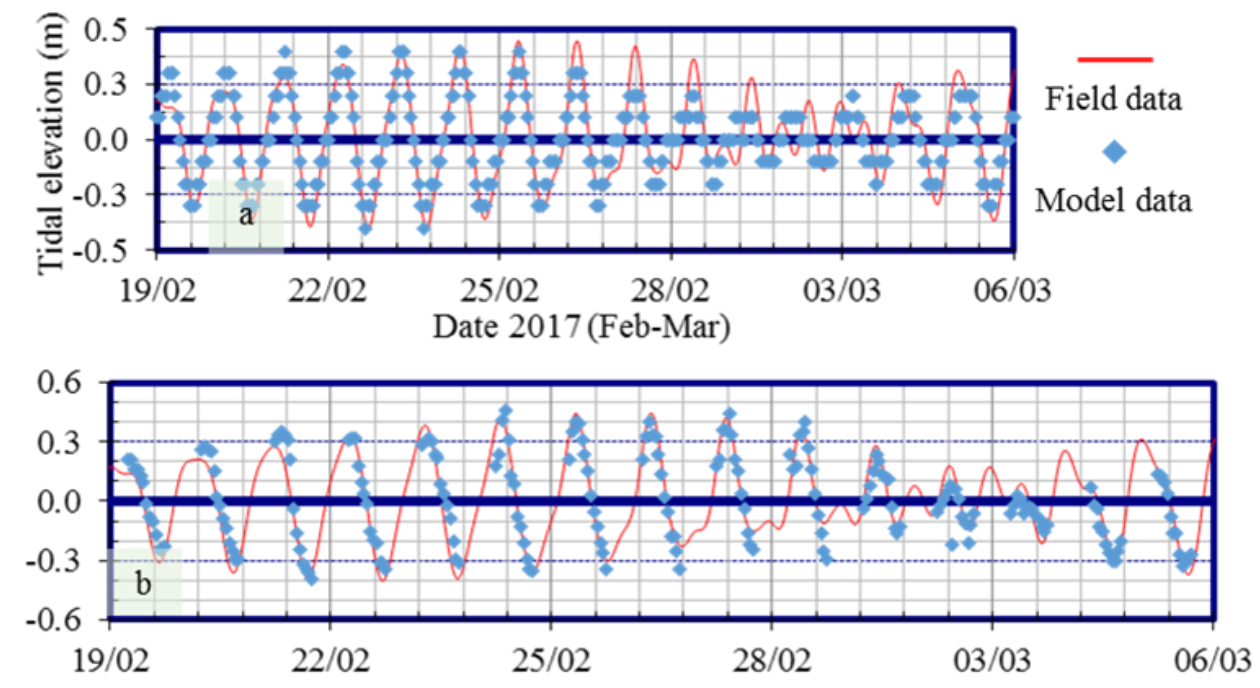

Fig. 10. Validation results of sea water surface elevation in local model at (a) Tanjung Priok Station and (b) field measurement location, T1. 

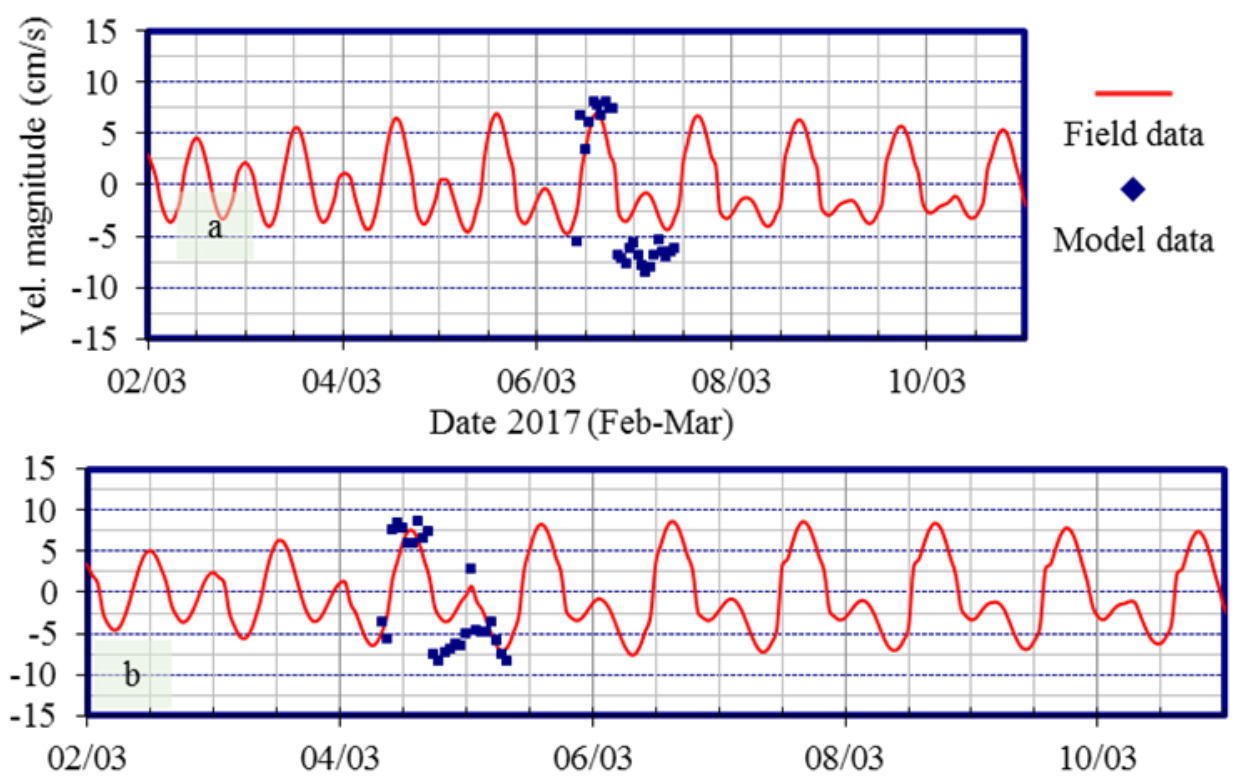

Fig. 11. Validation results of tidal current in local model at field measurement locations, (a) $\mathrm{C} 1$ and (b) $\mathrm{C}$.

\section{RESULTS AND ANALYSIS}

The analysis uses scenarios model results to assess the changes of sea water surface elevation and tidal-induced current due to reclamation and gate installation in the reclaimed area. The influences of the normal and flood discharge of rivers are also observed. The river flood discharge is determined and calculated as a 25 -year flood discharge. The investigated cross sections and points are given in Fig. 12. There are three cross sections and three investigated points. The 1 and 2 subscripts mark the start and end points of the sections, respectively.

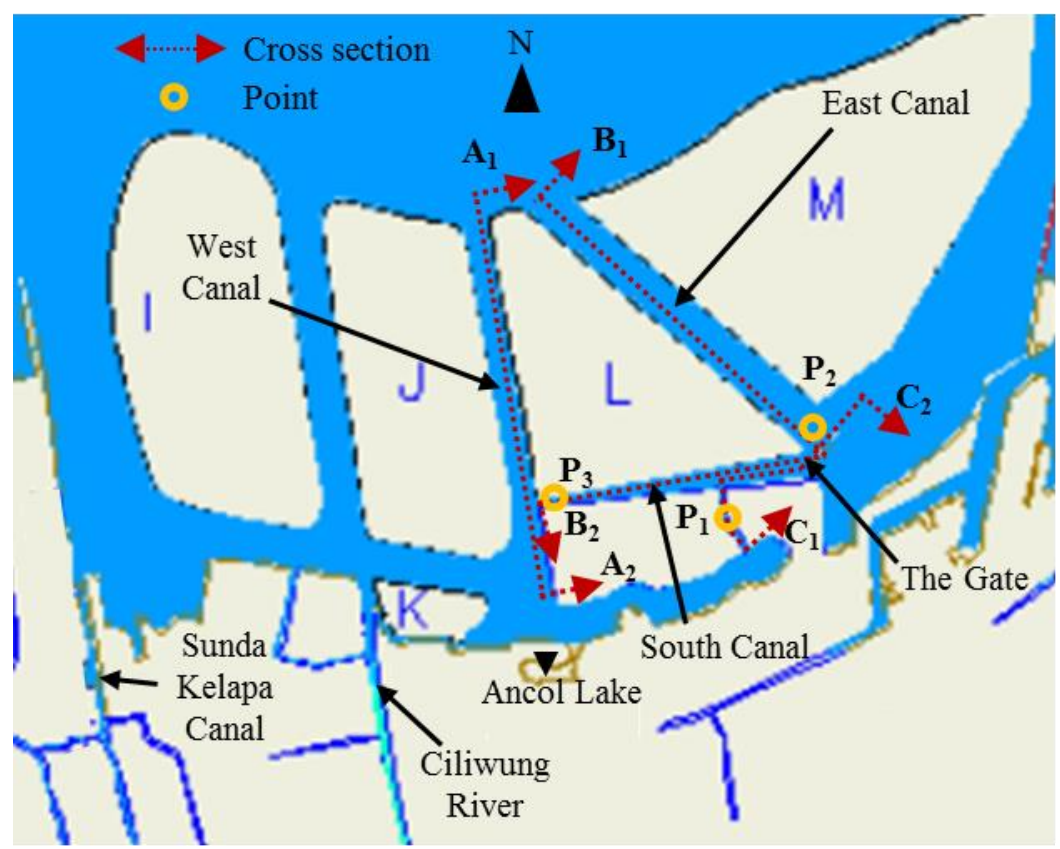

Fig. 12. Locations of canals, investigated cross sections (red line),and points (orange circle). Theblack circle is the gate location.

\section{A. The Effect on Sea Water Surface Elevation}

The change of sea water surface elevation influenced by the reclamation, and especially by the existence of the gate is investigated around L Island using three cross sections as indicated in Fig. 12 by red lines. The results are presented in the comparisons of the existing model against the scenarios model with normal and flood river discharges. 

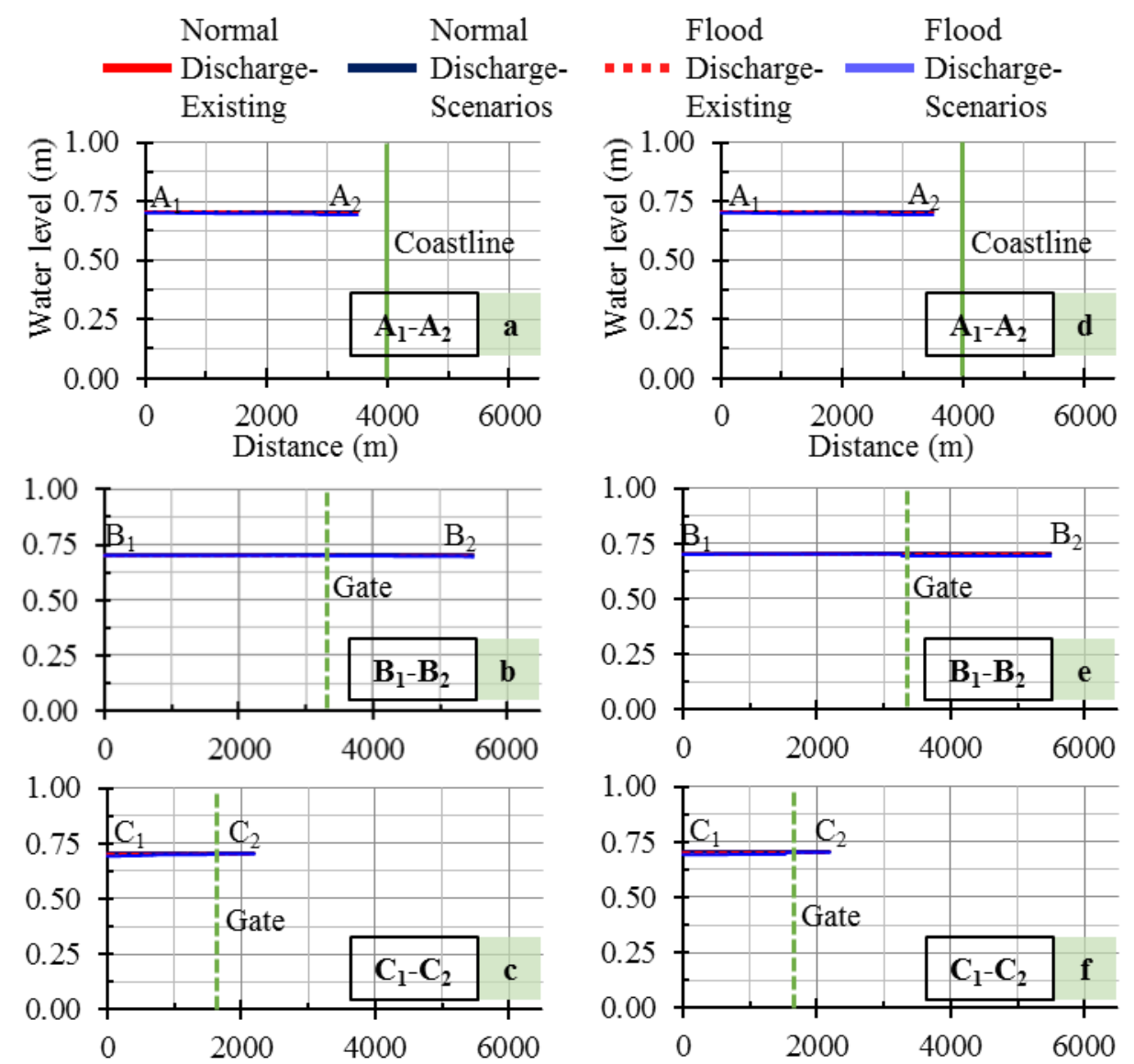

Fig. 13. Sea water surface elevation change at the investigated cross sections for $(a-c)$ for scenario A and (d-f) for scenario B.

The resulting comparison is shown in Fig. 13. Solid red and black lines show the sea water surface elevation for normal river discharge input. Dotted red and solid blue lines show the sea water surface elevation for flood river discharge input. The comparison for scenarios A and B are presented in Fig. 13a to 13c and Fig. 13d to 13f, respectively.

Cross section A1-A2 represents water conditions at the west side of $\mathrm{L}$ Island (west canal). The B1-B2 section represents the canal at the west and south side of L Island. C1-C2 shows the section from the south canal to M Island. Intuitively, the sea water surface elevation change affected by the gate shall be obtained from the B1-B2 and $\mathrm{C} 1-\mathrm{C} 2$ cross sections since they certainly pass the gate.

From all of the comparisons in Fig. 13, the normal river discharge input (solid red and black line) in scenarios $\mathrm{A}$ and $\mathrm{B}$ results in an insignificant sea water surface elevation increase. The rise is only few millimeters. This can be seen especially in the $\mathrm{C} 1-\mathrm{C} 2$ cross section, where the two lines are seen almost overlapping each other (see Figs. 13c and 13f). The flood river discharge input also results in an insignificant difference as seen in Fig. 13c and 13f. (dotted red and solid blue lines). So there is no significant water level rise due to flood, due to the open sea control volume, which has abundant space for fresh water to mix in.

\section{B. The Effect on Tidal Current}

The change in tidal current influenced by the reclamation and the gate is investigated along the coast of Jakarta Bay using three observed points in Fig. 12. The tidal current from every model and discharge input is recorded and compared. The resulting comparisons are given in Fig. 14, with the blue line representing the existing scenario, the red line for scenario A, and the green line for scenario B. Figures $14 \mathrm{a}$ to $14 \mathrm{c}$ show the comparison for normal river discharge input, and Fig. 14d to $14 \mathrm{f}$ are for the flood river discharge input (with return period of 25 years). The tidal current comparison at P1, P2, and P3 are presented in Fig. 14a and 14d, Fig. 14b and 14e, and Fig. 14c and $14 \mathrm{f}$, respectively.

For normal river discharge input, the reclamation in both scenarios shows a clear influence on the tidal current at the observed point. Figure 14a (at P1) shows amplitude magnification. However, the phase still shows a similar trend. The biggest velocity increment is given in Fig. 14a, the peaks are intensified by about $7 \mathrm{~cm} / \mathrm{s}$ for scenario A. Figure 14b (at P2) and 14c (at P3) show both amplitude and phase changes. 


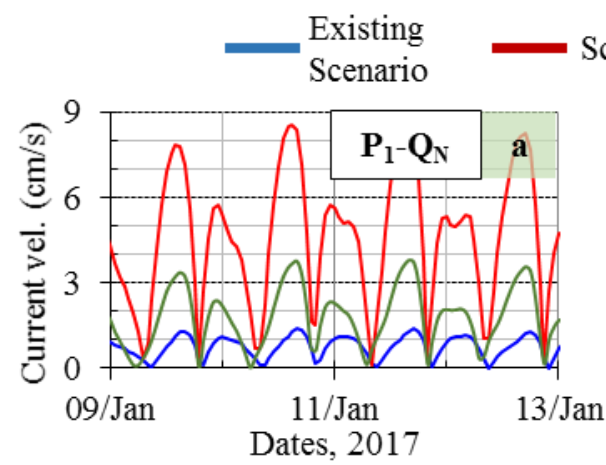

scenario A Scenario B
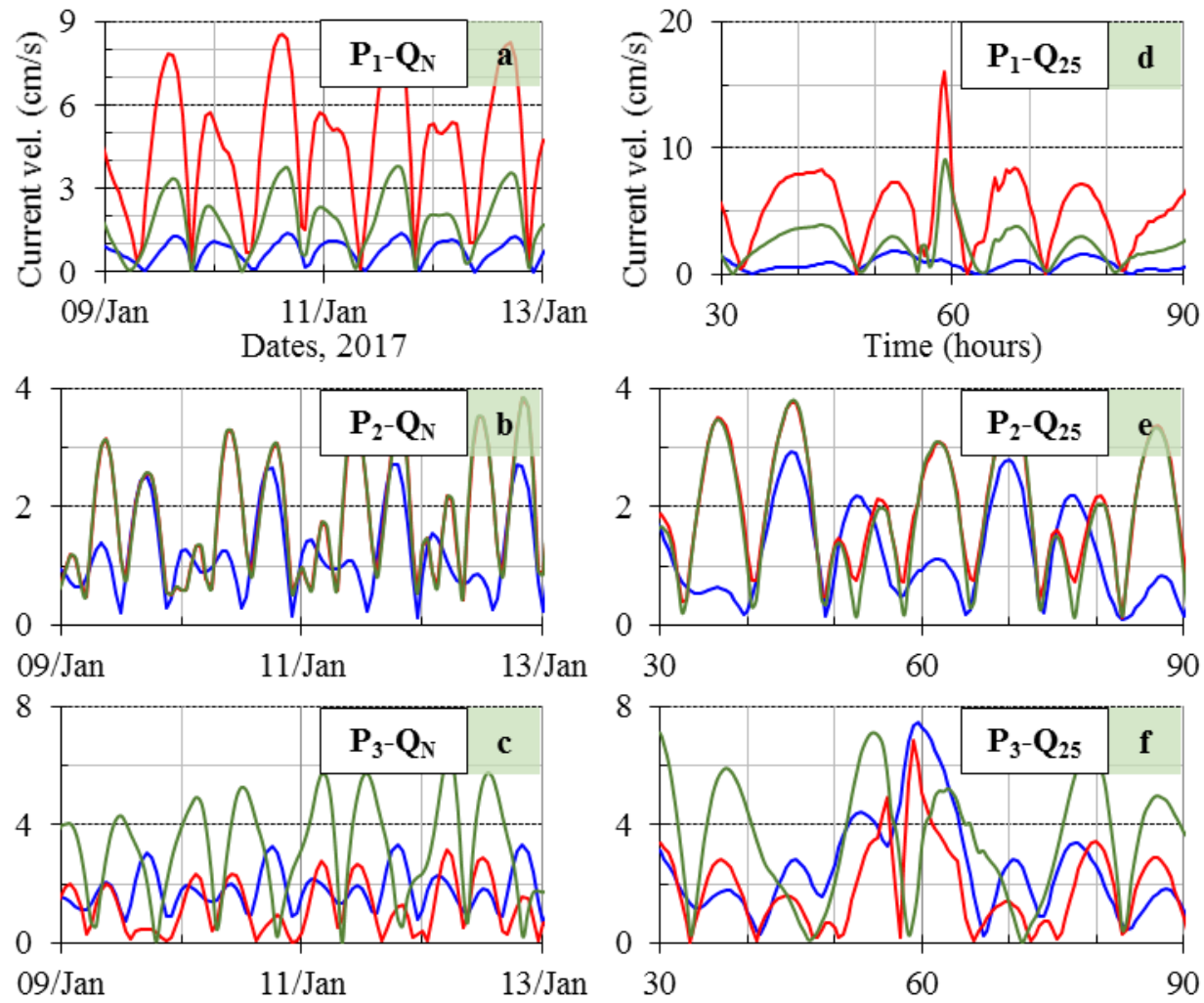

Fig. 14. Tidal current for all scenarios at the investigated points with a) points $\mathrm{P} 1, \mathrm{~b})$ point $\mathrm{P} 2$, c) point $\mathrm{P} 3$, for normal river discharge $\left(\mathrm{Q}_{\mathrm{N}}\right)$, and d) point $\mathrm{P} 1$, e) point $\mathrm{P} 2, \mathrm{f})$ point $\mathrm{P} 3$, for 25-year flood discharge $\left(\mathrm{Q}_{25}\right)$.

With the flood river discharge input, the amplitude of the tidal current at peak time (around hour-60) increases by around $14 \mathrm{~cm}$ as given in Fig.14d for scenario A. A slight decreasing peak is shown in Fig. 14f. A massive trend change in tidal current comparison is shown in Figs. 14e and 14f, with the amplitude and the phase shifting.

As seen in Fig. 12, the gate may influence P2 and P3 the most since discharge from the west or east side are blocked. Figure $14 \mathrm{~b}$ and $14 \mathrm{e}$ show the tidal current comparison in normal and flood discharge at P2. The result is a small difference when observing the scenarios A and B model, as seen in most of Fig. 14. The tidal current comparison at P3 is given in Figs. 14c and 14f, which show that scenario B gives a bigger velocity peak than scenario A. The phase in both figures is shifted.

Unexpectedly, the tidal current velocity difference between scenarios A and B is large at P1, as shown in Fig. $14 \mathrm{a}$ and $14 \mathrm{~d}$. In the model with normal river discharge input, the tidal current peaks in scenario A are as much as three to six times bigger than in scenario B and the existing model, respectively. The same is true for flood discharge, scenario A results in a velocity twice as large as scenario B.

\section{The Effect on Bed Change}

The yearly seabed change influenced by the reclamation and gate existence was investigated along the coast of Jakarta Bay using the three cross sections in Fig. 12. The bed elevations are presented in Fig. 15a, 15b, and 15e for $\mathrm{A} 1-\mathrm{A} 2, \mathrm{~B} 1-\mathrm{B} 2$, and $\mathrm{C} 1-\mathrm{C} 2$ respectively. The seabed change for a year at the A1-A2, B1-B2, and C1-C2 cross sections are given in Figs. 15d, 15e, and $15 \mathrm{f}$ respectively. The blue, red, and green lines represent three model results for the existing setup, scenario A (without gate), and scenario B (with gate).

Figures $15 \mathrm{a}$ to $15 \mathrm{c}$ show no significant difference in bed change. However, there is still bed change, although only in the order of centimeters, as seen in Figs. 15d to $15 \mathrm{f}$. The A1-A2 cross section, which is located in the west canal (from the north to the coast, black line), shows that the seabed increment is bigger as it approaches the coast, as seen in Fig. 15d. The seabed change in scenario B is bigger than in scenario A and the existing scenario at most points. Figure $15 \mathrm{~d}$ shows that the maximum change is $2.5 \mathrm{~cm}$ in one year. 


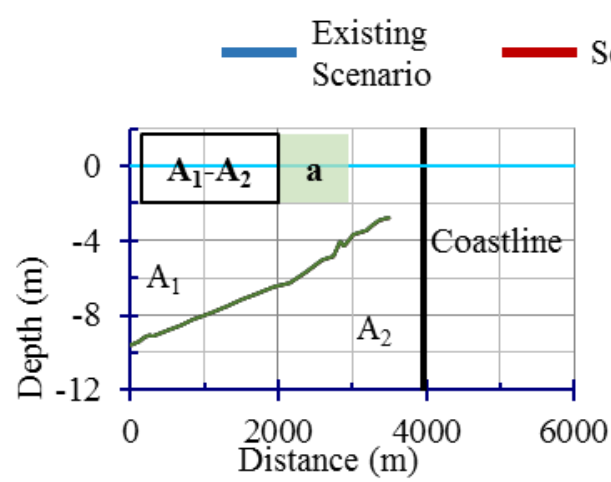

Scenario A Scenario B
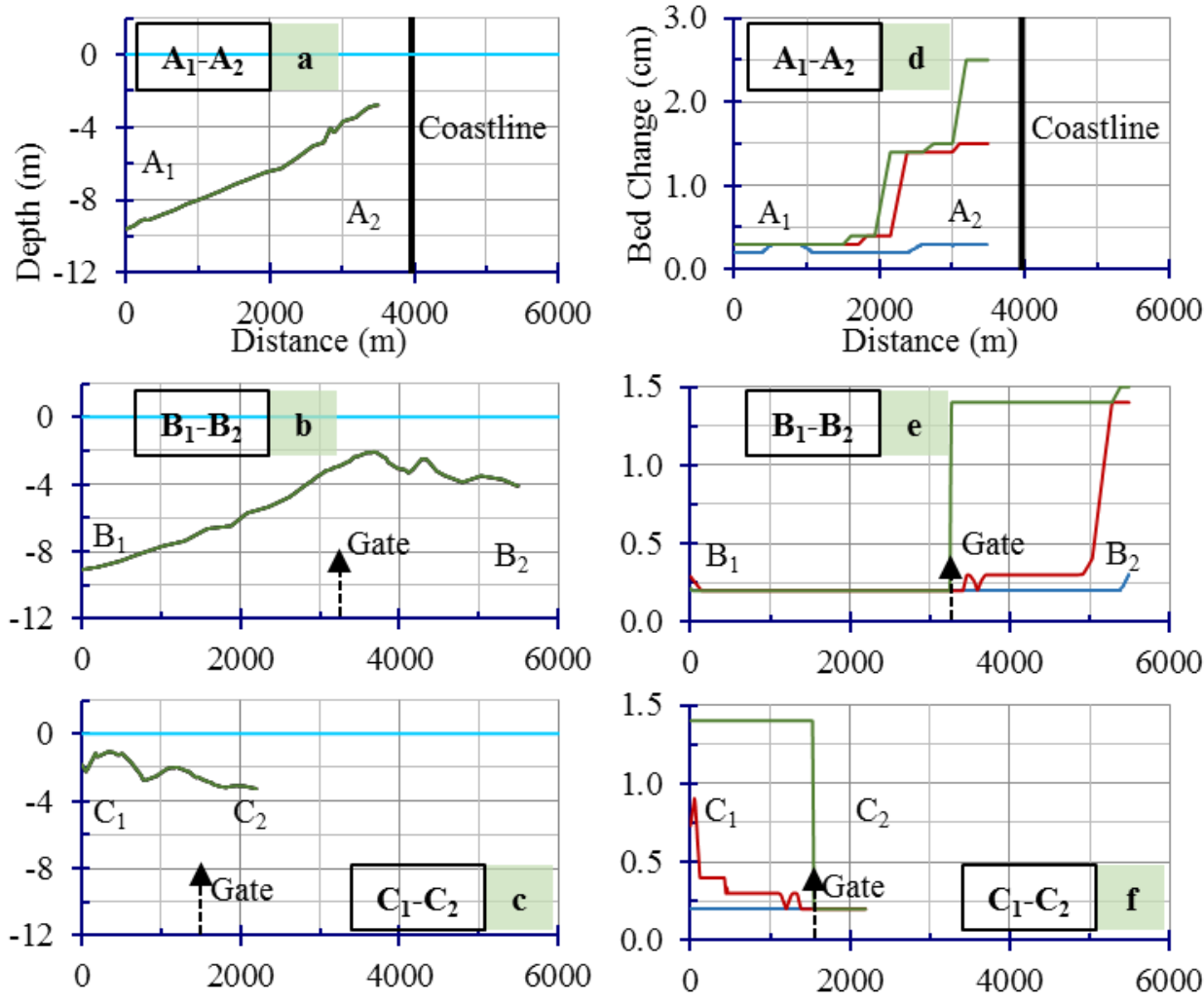

Fig. 15. (a-c) Seabed elevation and $(\mathrm{d}-\mathrm{f})$ bed change at the investigated cross sections for all scenarios.

The gate impact is shown in the B1-B2 and $\mathrm{C} 1-\mathrm{C} 2$ sections, which directly pass through the gate as shown in Figs. 15e and 15f, respectively. The west and south side of M Island only show 0.25 centimeters change, as seen in Fig. 15e at distances of $0-3,200 \mathrm{~m}$, and Fig. $15 \mathrm{f}$ at distances of $1,500-2,200 \mathrm{~m}$, respectively. In scenario B (green line) at a distance of about 3,200 m (B1-B2 cross section) and 1,500 m (C1-C2 cross section), a $1.4 \mathrm{~cm}$ seabed change occurs when the gate exists. As shown in Figs. 15e and 15f, scenario B results in a uniform sedimentation of $1.4 \mathrm{~cm}$ a year in the south canal. In scenario A, without the gate, the seabed change grows from 0 to $1.4 \mathrm{~cm}$ a year in the south canal (see red line in Fig. 15e).

\section{VI.CONCLUSION}

The local model around the area of interest presents a good and acceptable result in both sea water surface elevation and tidal-induced current validation against field measurement data and Indonesian Navy data. The existence of island reclamations do not produce large impacts on sea water elevations at the Jakarta Bay coast. However, an increase in tidal current exists of about $300 \%$ to $600 \%$ in the future canals between those new islands. This may result in erosive sea currents, which can be mitigated by lining the embankment of the future canals and present coastline. The construction of rubble mound revetment may avoid the occurrence of erosion. The reclamation and the existence of the gate do not pose a significant risk of bed profile change, they cause sedimentation only of the order of $\mathrm{cm}$ in a year.

In terms of seabed changes, scenarios A and B result in bigger changes than the existing condition. Scenario B gives the biggest change as the gate exists, especially in the south canal. Unexpectedly, the west side of L Island is also impacted by the gate's existence, the seabed deposit in scenario B is always higher than in scenario A.

There is a possibility of water elevation increase upstream in the river due to combinations of highest high water levels at the coast, flood river discharge, and land reclamation right on the estuary. This possibility should also be investigated.

\section{ACKNOWLEDGMENT}

The authors would like to thank the PT Pembangunan Jaya Ancol for funding this research. 


\section{REFERENCES}

[1] Xu Y, Cai Y, Sun T, Tan Q, "A multi-scale integrated modeling framework to measure comprehensive impact of coastal reclamation activities in Yellow River Estuary, China", Marine Pollution Bulletin, Vol. 122, 2017, pp. $27-37$.

[2] Peng B, Lin C, Jin D, Rao H, Jiang Y, Liu Yan, "Modeling the total allowable area for coastal reclamation: A case study of Xiamen, China", Ocean \& Coastal Management, Vol. 76, 2013, pp. 38-44.

[3] Gao GD, Wang XH, Bao XB, "Land reclamation and its impact on tidal dynamics in Jiaozhou Bay, Qingdao, China", Estuarine, Coastal and Shelf Science, Vol. 151, 2014, pp. 285-294.

[4] Feng L, He J, Ai J, Sun X, Bian F, Zhu X, "Evaluation for coastal reclamation feasibility using a comprehensive hydrodynamic framework: A case study in Haizhou Bay", Marine Pollution Bulletin, Vol. 1, 2015, pp. 182-190.

[5] Gao GD, Wang XH, Bao XW, Song D, Lin XP, Qiao LL, "The impacts of land reclamation on suspended-sediment dynamics in Jiaozhou Bay, Qingdao, China", Estuarine, Coastal and Shelf Science, In press-corrected proof, 2017.

[6] Ding P, Guo W, Wang XH, Ge J, Song D, "A system shift in tidal choking due to the construction of Yangshan Harbour, Shanghai, China" Estuarine, Coastal and Shelf Science, In press-corrected proof, 2017.

[7] Chua VP, Xu M, "A numerical study on circulation and volume transport in Singapore coastal waters", Journal of Hydro-environment Research, Vol. 12, 2016, pp. 70-90.

[8] Chua VP, Xu M, "A numerical study on flow and pollutant transport in Singapore coastal waters", Marine Pollution Bulletin, Vol. 111, 2016, pp. 160-177.

[9] Chua VP, Xu M, "A numerical study on land-based pollutant transport in Singapore coastal waters with a coupled hydrologichydrodynamic model", Journal of Hydro-environment Research, Vol. 14, 2017, pp. 119-142.

[10] Sommerfield CK, Cook TL, Wong KC, "Observations of tidal and springtime sediment transport in the upper Delaware Estuary", Estuarine, Coastal and Shelf Science, Vol. 72, 2007, pp. 235-246.

[11] Simmons JA, Harley MD, Marshall LA, Turner IL, Splinter KD, Cox RJ, "Calibrating and assessing uncertainty in coastal numerical models", Coastal Engineering, Vol. 125, 2017, pp. 28-41.

[12] Aragones L, Pagan JI, Lopez MP, Garcia-Barba J, “The impacts of Segura River (Spain) channelization on the coastal seabed”, Science of the Total Environment, Vol. 543, 2016, pp. 493-504.

[13] Zhu L, Li J, Zhang S, "Numerical model on the flow dynamics around the sediment-water interface in the tidal coastal area", Estuarine, Coastal and Shelf Science, Vol. 194, 2017, pp. 57-65.

[14] Tang J, Lyu Y, Shen Y, Zhang M, Su M, "Numerical study on influences of breakwater layout on coastal waves, wave-induced currents, sediment transport and beach morphological evolution", Ocean Engineering, Vol. 141, 2017, pp. 375-387.

[15] Azwar SA, Suganda E, Tijptoherijanto P, Rahmayanti H, "Model of Sustainable Urban Infrastructure at Coastal Reclamation of North Jakarta", Procedia Environmental Sciences, Vol. 17, 2013, pp. 452-461.

[16] Ajiwibowo H, Lodiwa KS, Pratama MB, Wurjanto A, "Field measurement and numerical modeling of tidal current in Larantuka Strait for renewable energy utilization", International Journal of Geomate, Vol. 13, 2017, pp. 124-131.

[17] Ajiwibowo H, Lodiwa KS, Pratama MB, Wurjanto A, "Numerical model of tidal current for power harvesting in Bangka Strait", International Journal of Earth Sciences and Engineering, In press-corrected proof, 2017.

[18] Ajiwibowo H, Pratama MB, Wurjanto A, "Assessment of tidal current power potency in Kelabat Bay, Indonesia”, International Journal of Engineering Technology, Vol. 9, 2017, pp. 3100-3110.

[19] Roelvink D, Thanh VQ, Reyns J, Wackerman C, Eidam EF, "Modelling suspended sediment dynamics on the subaqueous delta of the Mekong River", Continental Shelf Research, In press-corrected proof, 2017.

[20] Kampanis NA, Kozyrakis GV, Delis AI, Alexandrakis G, "Numerical modeling of sediment transport applied to coastal morphodynamics", Applied Numerical Mathematics, Vol. 104, 2016, pp. 30-46.

[21] User Guide to RMA2 WES Version 4.5. USA: US Army, Engineer Research and Development Center, Waterways Experiment Station, Coastal and Hydraulic Laboratory, 2005, ch. 2, pp 4-6.

[22] Tide Tables of Indonesia. Indonesia: Dinas Hidro-Oseanografi TNI-AL, 2017, ch. 31, pp. 221-227.

[23] Tidal Stream Tables of Indonesia Archipelago. Indonesia: Dinas Hidro-Oseanografi TNI-AL: 2017, ch. 11, pp 79-85.

[24] Matsumoto K, Takanezawa T, Ooe M, "Ocean tide models developed by assimilating TOPEX/POSEIDON altimeter data into hydrodynamical model: a global model and a regional model around Japan”, Journal of Oceanography, Vol. 56, 2000, pp. 567-581.

\section{AUTHOR PROFILE}

H. Ajiwibowo's research interests are in physical and numerical modeling of water resources and ocean engineering. He graduated from the Civil Engineering Department, Bandung Institute of Technology, in 1988 and a graduate program in the same field at Oregon State University (OSU), Corvallis, Oregon, USA. He graduated from OSU in 2002. He is currently an associate professor at the Faculty of Civil and Environmental Engineering, Bandung Institute of Technology, Indonesia.

M.B. Pratama's research interest is in hydrodynamic numerical modeling. He graduated from Bandung Institute of Technology in 2016 and is currently a research assistant for the Ocean Engineering Program, Bandung Institute of Technology, Indonesia. 